\title{
Maternal Age, Low Birth Weight and Early Neonatal Death in Tertiary Hospital in the Volta Region of Ghana
}

\author{
Innocent Afeke1, Lennox Mac-Ankrah², Ibrahim Jamfaru2, Kokou H. Amegan-Aho3, \\ Hintermann Kobina Mbroh", Sylvester Y. Lokpo', Edem Obum², Delali Geni', \\ Joseph Adu-Amankwaah', Verner N. Orish²
}

\footnotetext{
${ }^{1}$ Department of Medical Laboratory Science, School of Allied Health Science, University of Health and Allied Sciences, Ho, Ghana ${ }^{2}$ Department of Microbiology and Immunology, School of Medicine, University of Health and Allied Sciences, Ho, Ghana ${ }^{3}$ Department of Paediatrics, School of Medicine, University of Health and Allied Sciences, Ho, Ghana ${ }^{4}$ Maternity Department, Volta Regional Hospital, Ho, Ghana Email: iafeke@uhas.edu.gh
}

How to cite this paper: Afeke, I., Mac-Ankrah, L., Jamfaru, I., Amegan-Aho, K.H., Mbroh, H.K., Lokpo, S.Y., Obum, E., Geni, D., Adu-Amankwaah, J. and Orish, V.N. (2017) Maternal Age, Low Birth Weight and Early Neonatal Death in Tertiary Hospital in the Volta Region of Ghana. Open Journal of Pediatrics, 7, 254-262.

https://doi.org/10.4236/ojped.2017.74029

Received: October 3, 2017

Accepted: November 18, 2017

Published: November 21, 2017

Copyright $\odot 2017$ by authors and Scientific Research Publishing Inc. This work is licensed under the Creative Commons Attribution International License (CC BY 4.0).

http://creativecommons.org/licenses/by/4.0/ c) (i) Open Access

\begin{abstract}
Objectives: Current study sought to determine an association between Low Birth Weight (LBW) and early neonatal mortality at a resource limited country's referral hospital and to determine relationship between maternal age and birth outcomes. Method: A retrospective study analyzing data on births in the Volta Regional Hospital, Ghana from the period of November 2011 to June 2016. A total of 8279 births were analyzed. Results: Results suggest that teenage mothers $(8.60 \%)$ are more likely to give birth to pre-term babies than the elderly (6.60\%) and the adult mothers (4.61\%). LBW is highest among the teenage mothers $(12.69 \%)$ followed by the elderly mothers $(7.87 \%)$ and then the least among the adult mothers (6.48\%). Extremely Low Birth Weight (ELBW) and Macrosomia births were more observed among the elderly mothers $(0.90 \%$; $2.17 \%)$ than the teenage $(0.28 \% ; 0.14 \%)$ and adult mothers $(0.34 \% ; 1.61 \%)$ respectively. Data suggest that $100 \%$ of the ELBW were pre-term birth, $88.28 \%$ Very Low Birth Weight (VLBW), 34.56\% LBW and only $1.06 \%$ of the pre-term birth were with Normal Birth Weight (NBW). Death rate ranges from $50 \%$ for ELBW, 33.59\% for VLBW, $8.22 \%$ for LBW, 5.43\% for Macrosomia and 1.5\% for NBW. However, death rate distribution among the various age groups was statistically not significant $(P<0.106)$. Conclusions: Our study suggests that early neonatal death, especially deaths among ELBW and VLBW is still high at the VRH of Ghana and therefore there is the need for further studies into interventions to reduce death among neonates born with VLBW and ELBW.
\end{abstract}




\section{Keywords}

Low Birth Weight, Neonate; Early Neonatal Death, Maternal Age

\section{Introduction}

Early Neonatal Death (END) is a major public health problem facing both developed and developing countries worldwide. One of the major attributed causes of END is Low Birth Weight (LBW) which has been defined by the World Health Organization (WHO, 2004) as weight at birth of less than 2500 grams (5.5 pounds) [1].

Low Birth Weight is classified into Extremely Low Birth Weight (ELBW; $<1000$ g), Very Low Birth Weight (VLBW; $<1500 \mathrm{~g}$ ) and Low Birth Weight (LBW; $<2500$ g). More than 20 million infants worldwide, representing $15.5 \%$ of all births, are born with LBW, $95.6 \%$ of them in developing countries. It was reported that level of LBW in developing countries was $16.5 \%$, which was more than double the $7 \%$ level in developed regions [1]. For Africa, percentage of LBW infants was estimated to be $13.9 \%$ while that for Ghana was $11.0 \%$ as obtained from the Demographic and Health Survey reanalyzed in June 2003 [1].

Several factors have been attributed to a baby's low weight at birth. The majors among these are preterm birth (before 37 weeks' gestation) and restricted fetal (intrauterine) growth [2] [3] [4]. Few studies have shown association between early neonatal mortality with gestational age. The shorter the gestation, the smaller the baby and the higher the risk of morbidity, disability and death of a baby [5]. Among these studies, most have shown that the mortality range can vary 100 -fold across the spectrum of birth weight and rises continuously with decreasing weight [3] [5]. Some of the studies suggested that neonatal mortality was higher in the first 72 hours than after that period [5] [6] [7]. Furthermore, LBW due to restricted fetal growth affects the person throughout life and has been shown to be associated with poor growth in childhood and a higher incidence of adult diseases, such as type 2 diabetes, hypertension and cardiovascular diseases [1] Low Birth Weight was reported to have long been used as an important public health indicator to predict morbidity and mortality of neonates [1]. However, it has been recommended by WHO to be not a proxy for any one factor of either maternal or perinatal health outcomes. Generally, it is a good summary of a multifaceted public health problem such as the age of the mother, [5] [8] parity of the mother, [5] long term malnutrition, ill health; including malarial [9] and trichomoniasis [10] during pregnancy, mother herself being born with very low birth weight, hard work and poor pregnancy health care [11]. Paul et al. [2] on the contrary suggested gestational age to be a better predictive factor for the pattern of neonatal mortality than the birth weight which was previously suggested by WHO. Other studies are of the view that both gestational age and birth weight are major factors to predict neonatal mortality [12] [13] [14] [15]. Few studies have at- 
tempted to determine the associations, between maternal age, birth weight outcome and early neonatal death. There is limited data to explain the way in which low birth weight, gestational age and preterm birth risks interact with neonatal mortality in high mortality burden settings [15] In Africa and most importantly in Ghana, where teenage motherhood is common especially in the rural areas, there are limited research on association between early neonatal death and maternal risk factors. We therefore attempted to determine the associations between LBW, maternal age and early neonatal death in the referral regional hospital in the Volta Region of Ghana.

\section{Materials \& Method}

\subsection{Study Type and Study Site}

A retrospective study to determine an association between early neonatal death, birth weight and maternal age. The study was carried out at the Delivery and Pediatrics units of the Volta Regional Hospital, Ghana. The hospital is currently a regional hospital and a referral center with about 260 bed capacity that serves people within and beyond the Volta Region.

\subsection{Data Collection}

Study population was all the babies born alive either normal or caesarian delivery during the period of November 2011 to June 2016. All the relevant neonatal and maternal information in the mothers' folders were retrieved and recorded in a database. The endpoints were survival from birth to 7 days or death before or on the $7^{\text {th }}$ day from birth. The data of neonates with major congenital malformation and multiple birth (e.g. Twins) were excluded. Data of babies born at home before coming to the hospital were also excluded since birth weight of these babies were not recorded immediately after birth.

\subsection{Ethical Approval}

Permission was sought from the hospital's authority and ethical and scientific approval from the University of Health and Allied Sciences, School of Allied Health Sciences' Ethical and Scientific Approval Committee (UHAS-SAHS-ERSC: 025A/ 2017).

\subsection{Statistical Analyses}

Statistical analyses were done with Graph pad prism software, version 7. Before data analysis was done, data cleaning method described by Stevens (1984) [16] was used to identify outliers which are defined as point greater than 3 SD above or below the mean. Data with missing values were cleaned.

Multivariate significant testing of categorical variables was done using the chi-square test. Differences between groups in other variables were analyzed by the non-parametric (Two-tailed) Mann-Whitney U test. $P$ values of $<0.05$ were considered significant. 


\section{Results}

Records of 8279 babies born alive in our hospital during the period of November 2011 to June 2016 were analyzed. Table 1 shows the percentage distributions of the various birth weight classifications, maternal age distributions and endpoint of live births. It was evident that majority (78\%) of the mothers were in the adult age (20 - 35 years), which represented the reproductive age. Early neonatal mortality in this study was estimated to be $2.7 \%$.

Table 2 shows the percentage distributions of the various classes of birth weight among teenage mothers, adult mothers and elderly mothers. Our data suggested that ELBW and Macrosomia are more commonly observed among the elderly mothers than the teenage and the adult mothers. On the other hand, LBW and VLBW occurred more in the teenage mothers than in the adult and elderly mothers. Statistically there was very strong difference among the groups $P<0.0001$.

Table 3 compares the endpoint of the study which is either alive or death at the $7^{\text {th }}$ day of birth with the maternal age group and with birth weight classes. Our data suggested that there is no statistical difference in the maternal age group and the study outcome. However, very strong statistical difference was observed for the

Table 1. Frequencies of the various birth weight classes, maternal age and birth outcome after 7 days of birth.

\begin{tabular}{ccc}
\hline VARIABLE & FREQUENCY & PERCENTAGE \\
\hline BIRTH WEIGHT & 34 & 0.41 \\
ELBW & 128 & 1.56 \\
VLBW & 596 & 7.19 \\
LBW & 7392 & 89.28 \\
NBW & 129 & 1.56 \\
MACROSOMIA & 8279 & 100 \\
TOTAL & & 8.6 \\
MATERNAL AGE & 709 & 78 \\
TEENAGERS (12 - 19) & 6464 & 13.4 \\
ADULT (20 - 35) & 1106 & 100 \\
EDERLY (>35) & 8279 & \\
TOTAL & 8279 & 2.7 \\
BIRTH OUTCOME & 227 & 97.3 \\
DEATH & 8052 & 100 \\
ALIVE & & \\
TOTAL & & \\
\hline
\end{tabular}

Data presented as frequency and percentages in parenthesis, $\mathrm{f}(\%)$. ELBW = Extremely Low Birth Weight $(<1000 \mathrm{~g})$, VLBW $=$ Very Low Birth Weight $(>1000<1500 \mathrm{~g}), \mathrm{LBW}=$ Low Birth Weight $(>1500<2500 \mathrm{~g})$, NBW $=$ Normal Birth Weight $(>2500 \mathrm{~g})$, Macrosomia $(>4000 \mathrm{~g})$ 
Table 2. Distribution of birth weight classes among maternal age groups.

\begin{tabular}{cccccccc}
\hline $\begin{array}{c}\text { MATERNAL } \\
\text { AGE }\end{array}$ & ELBW & VLBW & LBW & NBW & MACROSOMIA TOTAL & \\
\hline $\begin{array}{c}\text { TEENAGERS } \\
(12-19)\end{array}$ & $2(0.28)$ & $15(2.12)$ & $90(12.69)$ & $601(84.77)$ & $1(0.14)$ & 709 & \\
$\begin{array}{c}\text { ADULTS } \\
(20-35)\end{array}$ & $22(0.34)$ & $91(1.41)$ & $19(6.48)$ & $5828(90.16)$ & $104(1.61)$ & 6464 & $P<0.0001$ \\
$\begin{array}{c}\text { ELDERLY } \\
(>35)\end{array}$ & $10(0.90)$ & $22(1.99)$ & $87(7.87)$ & $963(87.07)$ & $24(2.17)$ & 1106 & \\
\hline
\end{tabular}

Data presented as frequency and percentages in parenthesis, $\mathrm{f}(\%)$. ELBW $=$ Extremely Low Birth Weight, VLBW $=$ Very Low Birth Weight, LBW = Low Birth Weight, NBW = Normal Birth Weight.

Table 3. Birth outcome within 7 days of birth among the maternal age groups and birth weight classes.

\begin{tabular}{ccccc}
\hline VARIABLE & DEATH & ALIVE & TOTAL & \\
\hline MATERNAL $A G E$ & & & & \\
TEENAGERS (12 - 19) & $19(2.68)$ & $690(97.32)$ & 709 & $\boldsymbol{P}=\mathbf{0 . 1 0 6}$ \\
ADULTS $(20-35)$ & $167(2.58)$ & $6297(97.42)$ & 6464 & \\
ELDERLY (>35) & $41(3.71)$ & $1065(96.29)$ & 1106 & \\
BIRTH WEIGHT & & & & \\
ELBW & $17(50.00)$ & $17(50.00)$ & 34 & \\
VLBW & $43(33.59)$ & $85(66.41)$ & 128 & \\
LBW & $49(8.22)$ & $547(91.78)$ & 596 & \\
NBW & $111(1.50)$ & $7281(98.50)$ & 7392 & \\
MACROSOMIA & $7(5.43)$ & $122(94.57)$ & 129 &
\end{tabular}

Data presented as frequency and percentages in parenthesis, $\mathrm{f}(\%)$. ELBW = Extremely Low Birth Weight $(<1000 \mathrm{~g})$, VLBW $=$ Very Low Birth Weight $(>1000<1500 \mathrm{~g}), \mathrm{LBW}=$ Low Birth Weight $(>1500<2500 \mathrm{~g})$, NBW $=$ Normal Birth Weight $(>2500 \mathrm{~g})$, Macrosomia $(>4000 \mathrm{~g})$.

Birth Weight classes $P<0.0001$. It was evident that the highest early neonatal death occurred among the ELBW with 50\% of chance of survival. Early Neonatal Death follows a trend with ELBW (50\%) being the highest followed by VLBW (33.59\%), then LBW (8.22\%) and Macrosomia (5.43\%). This suggested that an increase in Birth Weight increases neonate's survival.

From Table 4 below, our data revealed that teenage mothers are more likely to give birth to pre-term babies than the adult mothers. Likewise, the elderly mothers are more likely to give birth to premature babies than the adult mothers. Overall, the teenage mothers are the most at risk for giving birth to pre-term babies. Statistically there was very strong difference observed among the groups $(P<0.0001)$. Comparing term of birth (gestation) among the Birth Weight classes, our data suggested a trend with increasing Birth Weight decreasing the chance of being born pre-term. It is evident that $100 \%$ of the ELBW were pre-term babies. Also, data revealed that pre-term babies ( $4.14 \%$ survive: $43.61 \%$ death) are less likely 
Table 4. Comparison of gestation periods among various maternal age groups, birth weight classes and effect on the outcome of birth within 7 days of birth.

\begin{tabular}{|c|c|c|c|c|}
\hline VARIABLE & PRE-TERM & TERM & TOTAL & \\
\hline \multicolumn{5}{|l|}{ MATERNAL AGE } \\
\hline TEENAGERS (12 - 19) & $61(8.60)$ & $648(91.40)$ & 709 & \multirow{3}{*}{$P<0.0001$} \\
\hline ADULTS (20 - 35) & $298(4.61)$ & $6166(95.39)$ & 6464 & \\
\hline ELDERLY (>35) & $73(6.60)$ & $1033(93.40)$ & 1106 & \\
\hline \multicolumn{5}{|l|}{ BIRTH WEIGHT } \\
\hline ELBW & $34(100)$ & $0(0)$ & 34 & \multirow{5}{*}{$P<0.0001$} \\
\hline VLBW & $113(88.28)$ & $15(11.72)$ & 128 & \\
\hline LBW & $206(34.56)$ & $390(65.44)$ & 596 & \\
\hline NBW & $78(1.06)$ & $7314(98.94)$ & 7392 & \\
\hline MACROSOMIA & $1(0.78)$ & $128(99.22)$ & 129 & \\
\hline \multicolumn{5}{|l|}{ BIRTH OUTCOME } \\
\hline DEATH & $99(43.61)$ & $128(56.39)$ & 227 & \multirow{2}{*}{$P<0.0001$} \\
\hline ALIVE & $333(4.14)$ & 7719 (95.86) & 8052 & \\
\hline
\end{tabular}

Babies born with gestational periods less than 37 weeks are considered Preterm while those above 37 weeks are Term.

to survive within the 7 days of birth as compared to the term babies (95.86\% survive: $56.39 \%$ death).

\section{Discussion}

We identified five statistically significant associations as far as maternal age, low birth weight and early neonatal death are concerned. This study was among the very few that were done in Ghana to determine risk factor that could be used to predict early neonatal mortality and this information could be used by policy makers to prevent high deaths among neonates. The overall early neonatal mortality estimated in this study was 27 deaths per 1000 live births which is high when compared to the current global neonatal deaths, estimated to be 19 deaths per 1000 live births [17]. Our estimated neonatal mortality rate was just part of the real neonatal mortality of this setting since it represented only deaths within 7 days of birth and not the first 28 days of life. It is of course, expected to be higher for the first 28 days of life since neonates especially those born with low birth weight and other congenital disorders are likely to be predisposed to nosocomial infections by the use of hospital devices on them. This finding suggested that neonatal mortality is still high in some geographic areas in the developing countries like Ghana.

Our analysis of data from this study revealed that both gestational age and neonatal birth weight when used together are better risk factors for predicting early neonatal mortality than birth weight only which has long been used to predict neonatal mortality as indicated by WHO [1]. Our finding was in agreement 
with other similar studies [12] [13] [14] [15] which suggested likewise. On the contrary, Paul et al. [2] suggested gestational age to be a better predictive factor for the pattern of neonatal mortality than the birth weight.

The current study revealed that teenage mothers are more likely to give birth to pre-term babies than the adult mothers. Likewise, the elderly mothers are more likely to give birth to premature babies than the adult mothers. Overall, the teenage mothers are the most at risk to give birth to pre-term babies. Statistically, there was very strong difference observed among the groups $(P<0.0001)$. Current study done in California by Baer et al. [18] revealed that women in their extremities of age are more likely to give birth to pre-term babies than their counterparts in the reproductive age (20 - 35 years). This might differ from one geographic area to another and might be race or ethnicity dependent. However, the mechanism of this occurrence is yet to be elucidated.

Our data suggested that ELBW and Macrosomia are more commonly observed among the elderly mothers than the teenage and the adult mothers. On the other hand, LBW and VLBW occurred more in the teenage mothers than in the adult and elderly mothers. Statistically there was very strong difference $(P<0.0001)$ among the groups. Similar trend was observed by Gupta et al. [5] where $42.5 \%$ of teenage mothers and $22 \%$ of the elderly ( $>35$ years) women gave birth to low birth weight babies. Reasons for these occurrences are not clear. Our study failed to determine significant difference between maternal age and early neonatal death. However, study done by Jacobsson et al. [8] reported higher incidence of neonatal mortality among mothers with age of 40 and above to those in their $20-29$ years of age.

Comparing term of birth (gestation) among the Birth Weight classes, our data suggested a trend of increasing Birth Weight and decreased chance of being born pre-term. It is evident that $100 \%$ of the ELBW were pre-term babies. Also, data revealed that pre-term babies (4.14\% survive: $43.61 \%$ death) are less likely to survive within the 7 days of birth as compared to the term babies (95.86\% survive: 56.39\% death). Statistically there was strong association $(P<0.0001)$ between gestational age and low birth weight.

\section{Conclusion}

Early neonatal mortality is high at the Volta Regional hospital, Ghana. The use of both gestational age and birth weight might be better predictive of early neonatal mortality than one risk factor. An extremity of maternal age is strongly associated with neonatal low birth weight and premature term. However, the reasons behind these occurrences are not clear hence calls for further research in these areas.

\section{Limitations}

It is important at this point to highlight the inherent limitations of this study. This study is a retrospective review of the maternity records of Volta Regional Hos- 
pital. We cannot fully ascertain if the procedure for weight measurements and other data collected for the new born babies followed standard procedure. Also, our study did not report on the mode of delivery of the babies and the complications that might have occurred. The genders of the babies have not been captured in our study. This might have given us information on whether male or female babies are more likely to survive during seven days of life. The demographical factors like educational level, economic status, and religious affiliation of the mothers have not been reported in our current study. These might have some bearing on early neonatal mortality.

\section{Acknowledgements}

We acknowledge the authorities of the VRH and staff of the Obstetrics and Pediatrics units of the Volta Regional Hospital for their support.

\section{Conflict of Interests}

The authors have not declared any conflict of interests.

\section{References}

[1] WHO, UNICEF (2004) Low Birthweight; Country, Regional and Global Estimates. New York UNICEF and WHO, New York.

[2] Paul, B., Saha, I., Mukherjee, A., Biswas, R., Roy, S. and Chaudhuri, R.N. (2011) Morbidity Pattern of Low-Birth-Weight Infants in an Urban Slum of Kolkata, India. The Journal of the Egyptian Public Health Association, 86, 39-43. https://doi.org/10.1097/01.EPX.0000399137.11413.e0

[3] Wilcox, A.J. (2001) On the Importance and the Unimportance of Birthweight. International Journal of Epidemiology, 30, 1233-1241. https://doi.org/10.1093/ije/30.6.1233

[4] Barker, D.J.P. (1990) The Fetal and Infant Origins of Adult Diseases. British Medical Journal, 17, 1111. https://doi.org/10.1136/bmj.301.6761.1111

[5] Gupta, M.K., Kakkar, M., Sethi, C. and Malhotra, A.K. (2014) Pattern of Morbility and Mortality in LBW Neonates: A Study from Jaipur. Journal of Evolution of Medical and Dental Sciences, 3, 1339-1345. https://doi.org/10.14260/jemds/2014/1989

[6] Bhatnagar, P.K. (2000) Study of Low Birth Weight Neonates. Medical Journal Armed Forces India, 56, 293-295. https://doi.org/10.1016/S0377-1237(17)30211-3

[7] WHO (2013) Neonatal Mortality. http://www.who.int/gho/child_health/mortality/neonatal_text/en/

[8] Jacobsson, B., Ladfors, L. and Milsom, I. (2004) Maternal Age and Pregnancy Outcome. The American College of Obstetrician and Gynecologist, 104, 727-733.

[9] Mahande, A.M. and Mahande, M.J. (2016) Prevalence of Parasitic Infections and Associations with Pregnancy Complications and Outcomes in Northern Tanznia: a Registry-Base Cross-Sectional Study. BMC Infectious Diseases, 16, 78. https://doi.org/10.1186/s12879-016-1413-6

[10] Kigozi, G.G., Brahnmbhatt, H., Wabwire-Mangen, F., et al. (2003) Treatment in Pregnancy and Adverse Outcomes of Pregnancy: A Subanalysis of a Randomized Trial in Rakai, Uganda. American Journal of Obstetrics \& Gynecology, 189, 1398-1400. 
https://doi.org/10.1067/S0002-9378(03)00777-4

[11] Sharma, M., Kumar, D., Huria, A. and Gupta, D. (2009) Maternal Risk Factors of Low Birth Weight in Chandigarh India. The Internet Journal of Health, 9, 15.

[12] Mardones, F., Marshall, G., Viviani, P., Villarroel, L., et al. (2008) Estimation of Individual Neonatal Survival Using Birth Weight and Gestational Age: A Way to Improve Neonatal Care. Journal of Health, Population and Nutrition, 26, 54-63.

[13] Lawn, J.E., Cousens, S. and Zupan, J. (2005) Lancet Neonatal Survival Steering Team. 4 Million Neonatal Deaths: When? Where? Why? Lancet, 365, 891-900. https://doi.org/10.1016/S0140-6736(05)71048-5

[14] Draper, E.S., Manktelow, B., Field, D.J. and James, D. (1999) Prediction of Survival for Preterm Births by Weight and Gestatinal Age: Restrospective Population Base Study. BMJ, 319, 1093-1097. https://doi.org/10.1136/bmj.319.7217.1093

[15] Marchant, T., Willey, B., Katz, J., Clarke, S., Kariuki, S., et al. (2012) Neonatal Mortality Risk Associated with Preterm Birth in East Africa, Adjusted by Weight for Gestational Age: Individual Participant Level Meta-Analysis. PLOS Medicine, 9, e1001292. https://doi.org/10.1371/journal.pmed.1001292

[16] Steven, J.P. (1984) Outliers and Influential Data Points in Regression Analysis. Psychological Bulletin, 95, 334-344. https://doi.org/10.1037/0033-2909.95.2.334

[17] UNICEF (2015) The Neonatal Period Is the Most Vulnerable Time for a Child. http://data.unicef.org/Child-Survival/neonatal-mortality

[18] Baer, R., Yang, J., Berghella, V., et al. (2017) Risk of Preterm Birth by Maternal Age at First and Second Pregnancy and Race/ Ethnicity. Journal of Perinatal Medicine. [Epub Ahead of Print] 